\title{
Analysis of Innovation in the Field of Data Transfer on Example of Segment Routing
}

\author{
Shloma Oleksandr ${ }^{1}$ \\ Volotka Vadym ${ }^{2}$
}

\begin{abstract}
Infocommunications of one of the most important and irreplaceable areas of the modern world. It is difficult to imagine a modern society without the Internet, communications, television. Each discovery in the field of infocommunications has a huge impact on humanity.
\end{abstract}

Keywords: Communications, protocols, data, MPLS, SR, network.

\section{IMPORTANCE OF TECHNOLOGY DEVELOPMENT}

Nowadays, the speed of technology development is many times greater than in the last century, and not surprisingly, this pace is increasing every year. However, not all spheres are developing at the same speed, which creates unfavorable conditions for the growth of other sectors. For example is the information industry, namely info-communications.

We all use mobile phones, personal computers and other modern technological devices. What do all these devices have in common? And what they have in common is that for a fullfledged functionality they need a network connection, and the actual data exchange. Most communication and switching protocols were developed over 20 years ago and are still in use. Undoubtedly, these communication protocols are outdated and can no longer cope with the required amount of data transfer. As a solution for this problem, was developed a segmented routing (SR) technology, which we will consider in more detail.

\section{About Segment Routing}

Let's consider segment routing technology in more detail. The concept of Segment Routing itself was developed by the SPRING working group as part of the IETF in 2016 [1]. In the data transmission of modern networks, a label system is used, the so-called programmable path, when the communication protocol does not need to look inside the packet, but just read the label and send the data. This technology has been around for 20 years and over the years it has proven to be effective. This technology is called MPLS (MultiProtocol Label Switching) [2]. It allows you to quickly and easily organize data transfer. Whether it is a large corporate network or a telecom operator. SR is an addition and optimization for MPLS and IPv6. Routing is defined by the sender and the communication node sends the data packet using transmission instructions called segments. But for the distribution of segments, two protocols are required:

1) LDP (Label Distribution Protocol) responsible for the distribution of labels [3];
${ }^{1}$ Kharkiv National University of Radio Electronics, 14 Nauky Ave, KharkivUA-61166,Ukraine, oleksandr.shloma@nure.ua

${ }^{2}$ Kharkiv National University of Radio Electronics, 14 Nauky Ave, KharkivUA-61166, Ukraine, vadym.volotka@nure.ua

2) RSVP (Resource ReSerVation Protocol) responsible for the reservation of network resources. [4]

These two protocols are control protocols that increase the load on the physical part of the routing and they add some complexity. They must interact with the IGP (Interior Gateway Protocol) [5] and, if somewhere here is a mistake, they can completely reset the all data. The IGP is responsible for transmitting route information.

The SR developers asked themselves to abandon of LDP and RSVP, because if we need identifiers of routers and their interfaces for data transfer, we can use IGP directly with OSPF (Open Shortest Path First). In OSPF protocols contain all information that we need about network connections, which can be supplemented. OSPF is a dynamic routing protocol that searches for the shortest path for data transfer. Transport labels will be directly distributed through the IGP, bypassing the LDP. Thus, some steps in packet processing are skipped, and as a result - performance increases.

\section{RESULTS}

SR without the extra efforts and problems can complement MPLS without changing the forwarding levels. Then the segments will be transmitted as MPLS tags, and the list of segments as a stack of tags. SR can also be used in IPv6 technology. The so-called new type of SR header (Segment Routing Header) is used. In it, the segment is converted to an IPv6 address, and the list of segments is encoded into a list of IPv6 addresses in the routing header. In this case, the active segment is indicated by the recipient address in a new header.

\section{REFERENCES}

[1] RFC 8402 Segment Routing Architecture [Electronic resource] Resource access mode: https://www.protocols.ru/WP/rfc8402/.

[2] Segment Routing [Electronic resource] - Resource access mode: http://internetinside.ru/segmentnaya-marshrutizaciya//.

[3] LDP protocol [Electronic resource] - Resource access mode: http://iptcp.net/protokol-ldp.html

[4] Reservation protocols [Electronic resource] - Resource access mode: https://www.opennet.ru/docs/RUS/inet_book/4/44/rsv_4496.html

[5] Inerir Gateway Protocol [Electronic source[ - Resource access mode: https://searchsecurity.techtarget.com/definition/IG 